\title{
Transition metal complexes of an isatinic quinolyl hydrazone
}

\author{
Hussein S Seleem
}

\begin{abstract}
Background: The importance of the isatinic quinolyl hydrazones arises from incorporating the quinoline ring with the indole ring in the same compound. Quinoline ring has therapeutic and biological activities. On the other hand, isatin (1H-indole-2,3-dione) and its derivatives exhibit a wide range of biological activities. Also, the indole ring occurs in Jasmine flowers and Orange blossoms. Recently, the physiological and biological activities of quinolyl hydrazones arise from their tendency to form metal chelates with transition metal ions. In this context, we have reported to isolate, characterize and study the biological activity of some transition metal complexes of an isatinic quinolyl hydrazone; 3-[2-(4-methyl quinolin-2-yl)hydrazono] indolin-2-one.

Results: Mono- and binuclear as well as dimeric chelates were obtained from the reaction of a new isatinic quinolyl hydrazone with Fe(III), $\mathrm{Co}(\mathrm{II}), \mathrm{Ni}(\mathrm{II}), \mathrm{Cu}(\mathrm{II}), \mathrm{VO}(\mathrm{II})$ and $\mathrm{Pd}(\mathrm{II})$ ions. The ligand showed a variety of modes of bonding viz. (NNO) ${ }^{2-},(\mathrm{NO})^{-}$and $(\mathrm{NO})$ per each metal ion supporting its ambidentate and flexidentate characters. The mode of bonding and basicity of the ligand depend mainly on the type of the metal cation and its counter anion. All the obtained $\mathrm{Pd}(\mathrm{II})$ - complexes have the preferable square planar geometry $\left(\mathrm{D}_{4 \mathrm{~h}^{-}}\right.$symmetry) and depend mainly on the mole ratio (M:L).

Conclusion: The effect of the type of the metal ion for the same anion $\left(\mathrm{Cl}^{-}\right)$is obvious from either structural diversity of the isolated complexes $\left(\mathrm{O}_{h}, T_{d}\right.$ and $\left.D_{4 h}\right)$ or the various modes of bonding. The isatinic hydrazone uses its lactim form in all complexes $\left(\mathrm{Cl}^{-}\right)$except complex $\mathbf{5}\left(\mathrm{SO}_{4}{ }^{2-}\right)$ in which it uses its lactam form. The obtained Pd(II)complexes (dimeric, mono- and binuclear) are affected by the mole ratio $(M: L)$ and have the square planar ( $D_{4 h}$ ) geometry. Also, the antimicrobial activity is highly influenced by the nature of the metal ion and the order for $\mathrm{S}$. aureus bacteria is as follows: Nickel(II) > Vanadyl(II) > Cobalt(II) > Copper(II) $\approx$ Palladium(II) >> Iron(III).
\end{abstract}

\section{Background}

Importance of the quinoline nucleus arises from its presence in a group of potent alkaloids e.g. quinine and cyanine dyes. Also, in analytical reagents e.g. oxine and in few synthetic drugs e.g. anti-malaria [1,2]. On the other hand, isatin (1H-indole-2,3-dione) and its derivatives exhibit a wide range of biological activities $[3,4]$. The indole ring occurs in Jasmine flowers and Orange blossoms [1]. The incorporation of the quinoline ring with the indole ring may enhance the biological activity of such class of compounds. In continuation of my interest on the complexation of quinolyl hydrazones [5-9], this study is planned to isolate, characterize and study the biological activity of some transition metal complexes

Correspondence: hsseleem@yahoo.com

Ain Shams University, Faculty of Education, Department of Chemistry, Roxy, Cairo, Egypt
(Fe(III), Co(II), Ni(II), Cu(II), VO(II) and Pd(II)) of a new isatinic quinolyl hydrazone $\left(\mathrm{H}_{2} \mathrm{~L}\right)$; 3-[2-(4-methyl quinolin-2-yl)hydrazono]indolin-2-one (Scheme 1).

\section{Results and discussion}

Characterization of the hydrazone

The results of elemental analysis of the investigated hydrazone $\left(\mathrm{H}_{2} \mathrm{~L}\right.$; Scheme 1$)$ are in good agreement with the proposed molecular formula; $\mathrm{C}_{18} \mathrm{H}_{14} \mathrm{~N}_{4} \mathrm{O}$ (302.36): Calcd.: $\mathrm{C}$, 71.50; H, 4.68; N, 18.53 Found: C, 71.40; H, 4.50; N, 18.60. The IR spectrum showed very strong bands at 3333, 1684 and $1633 \mathrm{~cm}^{-1}$ assignable to $v(\mathrm{NH}), v(\mathrm{C}=\mathrm{O})$ and $v(\mathrm{C}=$ $\mathrm{N})$, respectively, confirming the lactam nature of $\mathrm{H}_{2} \mathrm{~L}$. Also, the ${ }^{1} \mathrm{H}$ NMR spectral data of the ligand in $\mathrm{d}_{6}$-DMSO relative to TMS (Figure 1) provide a further support of the lactam nature of the hydrazone. The mass spectrum of the ligand showed the $\mathrm{M}^{+}$peak at $m / z=302$ and the base 


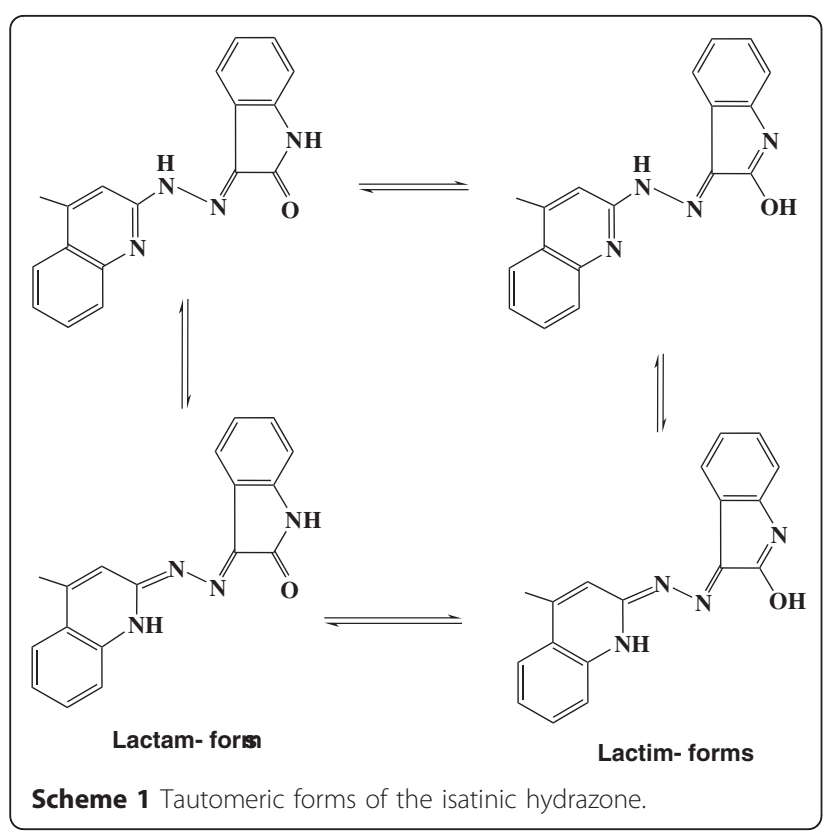

peak at $m / z=273$ confirming its formula weight. Furthermore, the mass fragmentation pattern (Scheme 2) supported the suggested structure of the ligand.

\section{Effect of solvent on the spectra of the hydrazone}

In this study, the electronic absorption spectra of the hydrazone $\left(2 \times 10^{-5} \mathrm{M}\right)$ were recorded in solvents of various polarities (Table 1 and Figure 2). The hydrazone displays mainly three bands, the shortest UV- bands $\left(\lambda_{1}=205-275\right.$ and $\left.\lambda_{2}=384-401 \mathrm{~nm}\right)$ are best ascribed to $\pi-\pi^{*}$ transitions of the aromatic system and they are solvent sensitive bands whereas, the longest UV- band $\left(\lambda_{3}=468-476 \mathrm{~nm}\right)$ is a strong broad band reflecting its charge transfer $(\mathrm{CT})$ nature $[9,10]$. The latter band impacts the ligand its red color. Most bands suffered a red shift on increasing the solvent polarity. Also, the less intense $n-\pi^{*}$ transitions of the $\mathrm{C}=\mathrm{O}$ and $\mathrm{C}=\mathrm{N}$ are hidden under the more intense CT bands, especially in polar solvents. Correlation of the band shift $(\Delta \tilde{v})$ with the solvent parameters [8,11-13]viz. 1/D; ( $D$ is the

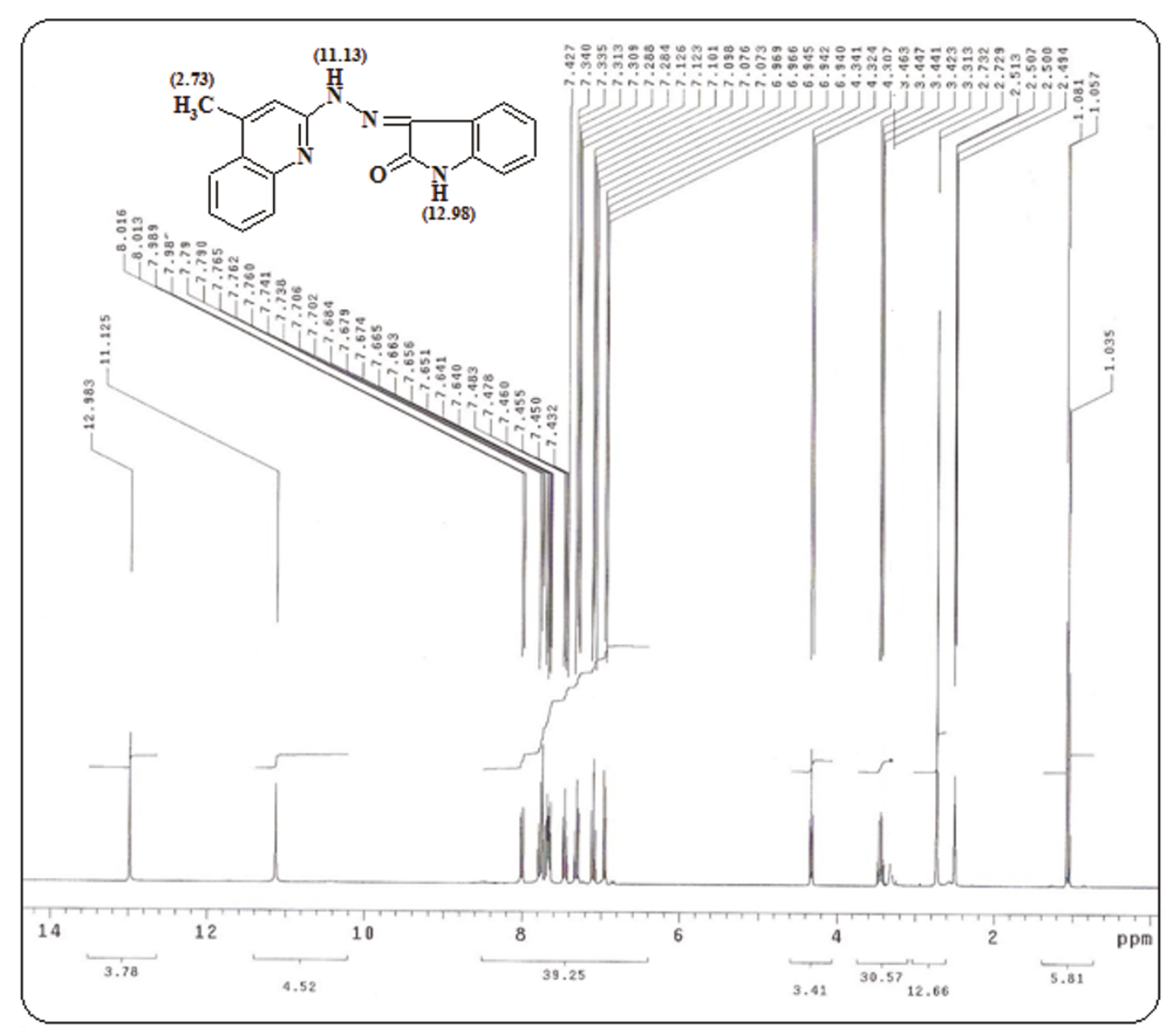

Figure $1{ }^{1} \mathrm{H}$ NMR spectral data of $\mathrm{H}_{2} \mathrm{~L}$ in DMSO- $\mathrm{d}_{6} ; \delta=7.12-7.43$ for aromatic protons $(9 \mathrm{H})$. 


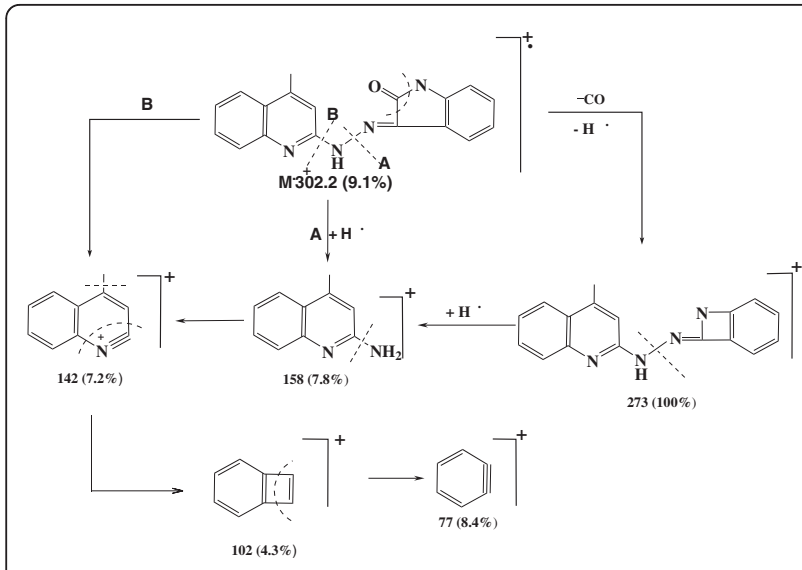

Scheme 2 Mass fragmentation pattern of the isatinic hydrazone.

dielectric constant), Kosower's (Z), Dimroth-Reichardt's $\left(E_{T}\right)$, Kamlet-Taft's $\left(\alpha, \beta, \pi^{*}\right)$ or Gutmann's donoracceptor numbers (DN, AN) is not satisfactory indicating that $\Delta \tilde{\nu}$ is affected by more than one parameter e.g. polarity, donor- acceptor and acid- base properties of the solvents as well as solute- solvent interactions and $\mathrm{H}$ - bonding.

\section{Characterization of the isatinic complexes}

The isatinic hydrazone was allowed to react with copper (II), cobalt(II), nickel(II), and iron(III) chlorides, as well as vanadyl (II) sulfate monohydrate at the mole ratio; 1:1 (Scheme 3). Also, in an attempt for investigating the effect of the mole ratio on the products, the isatinic hydrazone was allowed to react with palladium(II)-chloride at the mole ratios 1:1, 1:2 and 2:1 (M:L). These reactions afforded dimeric, mono- and binuclear complexes (Table 2 and Scheme 4). The obtained Pd(II)- complexes have the preferable square planar $\left(\mathrm{D}_{4 \mathrm{~h}}\right)$ geometry [14]. In case of the ratio 1:2 (M:L), a base catalyzed dimerization occurs (Scheme 4; complex 7). The proposed structures of the complexes are in good harmony with the results of the elemental analyses. The isatinic hydrazone showed a variety of modes of bonding towards the different metal ions viz. neutral NO bidentate using its lactam form (complex $\mathbf{5}$; $\mathrm{SO}_{4}{ }^{-}$), mono anionic $\mathrm{NO}$ bidentate using its lactim form without $\mathrm{O}$ - bridging (complexes $\mathbf{1}, \mathbf{3}$ and 8) or with $\mathrm{O}$ bridging (complex 2). In case of complexes 4, 6 and 7, the hydrazone behaves as dianionic NNO tridentate with or without $\mathrm{O}$ - bridging. However, the latter mode of bonding is not observed in our previous study for a similar isatinic hydrazone; 3-[2-(4,8-dimethylquinolin-2-yl)hydrazono] indolin-2-one [10]. This is due to the presence of the Megroup in the 8- position in close proximity to the heterocyclic $\mathrm{N}$ - atom of the quinoline ring [6]. Hence, the degree of basicity and deprotonation of the hydrazone as well as the mode of bonding are highly affected by the position of the Me-group. The dimeric complexes ( 2 and 7 ) have the trans arrangement and are formed via lactim bridging, whereas the binuclear complex (8) is formed via chloride bridging. Characterization of the obtained complexes was achieved via elemental analyses, magnetic and conductivity measurements as well as spectral studies.

\section{IR spectra of the complexes}

Most complexes showed a broad band in the range $3463-3203 \mathrm{~cm}^{-1}$ due to $v(\mathrm{OH})$ of the associated water or ethanol molecules. The band at $1633 \mathrm{~cm}^{-1}$ assignable to $v(\mathrm{C}=\mathrm{N})$ in the free ligand was shifted to higher or lower values indicating its participation in the chelation with $\pi$ - electron delocalization. In all complexes, the band located at $1684 \mathrm{~cm}^{-1}$ due to $v(\mathrm{C}=\mathrm{O})$ of the free ligand disappeared indicating the participation of the lactim form in the chelation. An exception is complex $\mathbf{5}$ in which this band is shifted to lower wave number; $1670 \mathrm{~cm}^{-1}$. The variable intensity bands of the quinoline ring of the free hydrazone at 1554,1482 and $1455 \mathrm{~cm}^{-1}$ are greatly altered as a result of the complexation.

The free sulfate ion belongs to the high symmetry $T_{d}$ point group. Of the four fundamentals, only $v_{3}$ and $v_{4}$ are IR active; bands at $\sim 1105$ and $\sim 615 \mathrm{~cm}^{-1}$, assignable to $v_{3}$ stretching $[v(\mathrm{SO})]$ and $v_{4}$ bending $[\delta(\mathrm{OSO})]$ modes, respectively $[15,16]$. The $v_{1}$ stretching $[\mathrm{v}(\mathrm{SO})]$ and $v_{2}$ bending $[\delta(\mathrm{OSO})]$ fundamentals are not IRactive. However, the coordination of $\mathrm{SO}_{4}{ }^{2-}$ to metal ions in a bidentate fashion decreases the symmetry of the group and the $v_{3}$ and $v_{4}$ modes may be split [15-17]. For the sulfato complex (5) in this study, the chelating bidentate nature of the $\mathrm{SO}_{4}{ }^{2-}$ group is indicated by the

Table 1 Electronic spectral data*of the isatinic hydrazone in various solvents

\begin{tabular}{cccccccccccc}
\hline Solvent & DMSO & DMF & 2-Propanol & MeOH & EtOH & Acetone & Dioxane & THF & Ethyl ether & Benzene & Ethyl acetate \\
\hline$\lambda_{1}$ & 264 & 267 & 240 & 206 & 205 & -- & 228 & 248 & 227 & 275 & 265 \\
$\varepsilon_{1}$ & 17000 & 13700 & 12250 & 53800 & 64250 & -- & 27980 & 19780 & 30890 & 8750 & 15590 \\
$\lambda_{2}$ & 390 & 389 & 386 & 384 & 384 & 396 & 401 & 390 & 391 & 397 & 388 \\
$\varepsilon_{2}$ & 23630 & 21300 & 18650 & 21700 & 25750 & -- & 23660 & 22860 & 23700 & 30500 & 26000 \\
$\lambda_{3}$ & 472 & 468 & 474 & 475 & 476 & 470 & 475 & 475 & 472 & -- & 472 \\
$\varepsilon_{3}$ & - & 18060 & 23520 & 19850 & 18170 & 21480 & 28000 & 15000 & 17500 & -- & -- \\
\hline
\end{tabular}

${ }^{*} \lambda$ in $\mathrm{nm}$ and $\varepsilon$ in $(\mathrm{cm} \mathrm{mol} / \mathrm{L})^{-1}$. 


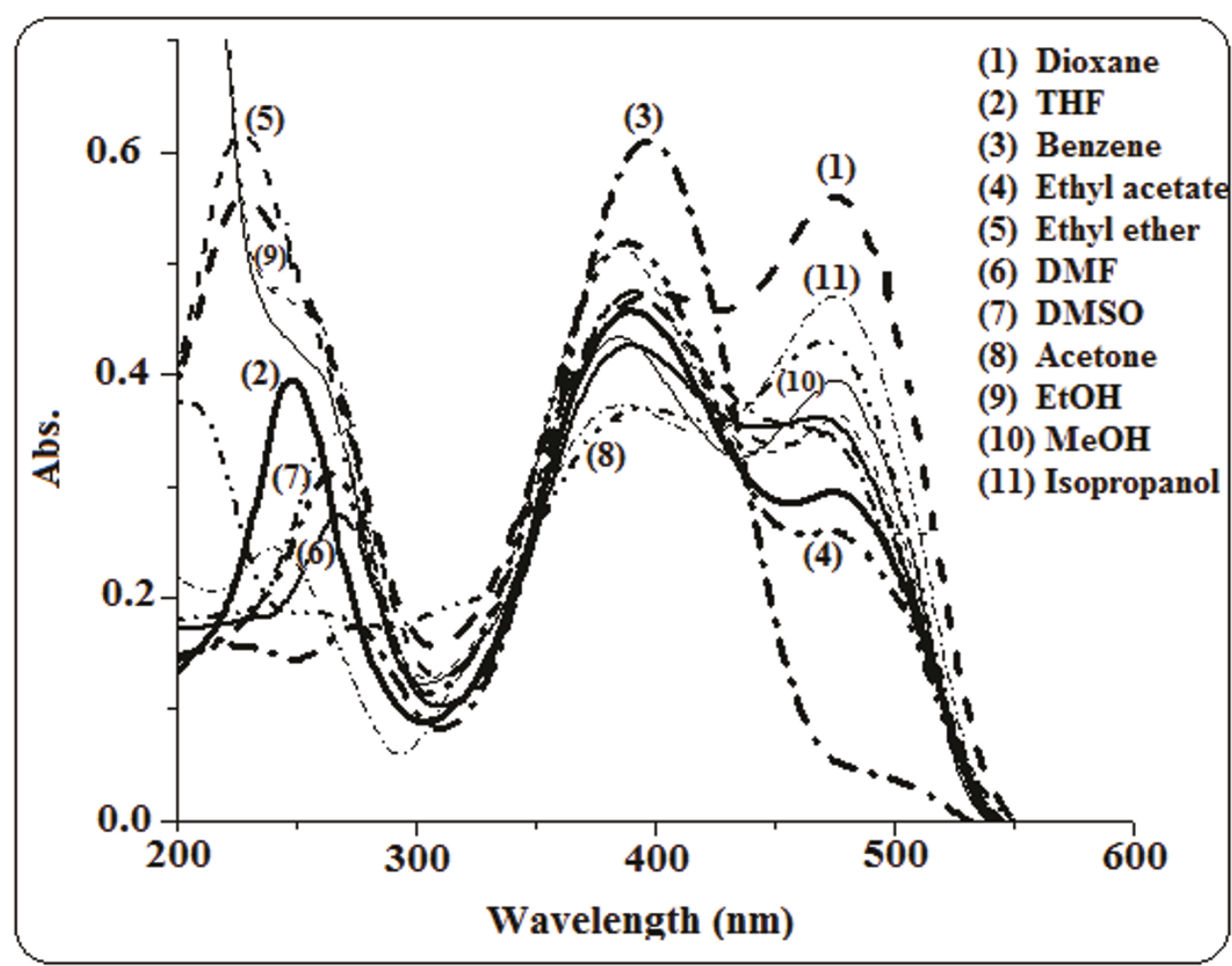

Figure 2 Electronic absorption spectra of $\mathrm{H}_{2} \mathrm{~L}$ in various solvents.

strong band at $1100 \mathrm{~cm}^{-1} ; v_{3}(\mathrm{~S}-\mathrm{O})$ as well as a medium band at $657 \mathrm{~cm}^{-1} ; v_{4}[\delta(\mathrm{OSO})]$ characteristic for the tetrahedral $\left(T_{d}\right)$ point group. These spectral features suggest a low symmetry for the sulfato ligand in the complex.

\section{Magneto chemistry}

The magnetic properties of the complexes provide valuable information for distinguishing their stereochemistry. Iron (III) has a $3 \mathrm{~d}^{5}$ configuration and its complexes may be either high-spin ( $\mathrm{S}=5 / 2)$, intermediate-spin ( $\mathrm{S}$ $=3 / 2)$ or low-spin $(S=1 / 2)$, however, the majority of iron(III)- complexes are high-spin. The effective magnetic moment $\left(\mu_{\mathrm{eff}}\right)$ of the iron(III)- complex (1) has the value 6.13 B.M. (Table 3) which is consistent with five unpaired electrons suggesting an $\mathrm{sp}^{3} \mathrm{~d}^{2}$ hybridization, and falls within the range reported for high spin $\mathrm{O}_{\mathrm{h}}$ geometry [18]. The copper(II)- complex (4), $3 \mathrm{~d}^{9}$-system and oxovanadium (IV) complex (5); $3 \mathrm{~d}^{1}$-system exhibit $\mu_{\text {eff }}$ values of 1.83 and 1.91 B.M. (Table 3) indicating the

Table 2 Analytical and physical data of the isatinic complexes

\begin{tabular}{|c|c|c|c|c|c|c|c|c|}
\hline \multirow[b]{2}{*}{ No } & \multirow[b]{2}{*}{$\begin{array}{c}\text { Reactants } \\
\text { Metal salt }+\mathrm{H}_{2} \mathrm{~L}\end{array}$} & \multirow[b]{2}{*}{$\begin{array}{l}\text { Complex } \\
\text { (F.W.) }\end{array}$} & \multirow[b]{2}{*}{ Color } & \multirow[b]{2}{*}{$\%$ Yield } & \multicolumn{4}{|c|}{ Elemental Analysis; \%Found/(Calcd.) } \\
\hline & & & & & C & $\mathrm{H}$ & $\mathbf{N}$ & $M$ \\
\hline 1 & $\mathrm{FeCl}_{3} .6 \mathrm{H}_{2} \mathrm{O}$ & {$\left[\mathrm{Fe}(\mathrm{HL})_{2} \mathrm{Cl}\left(\mathrm{H}_{2} \mathrm{O}\right)\right] .1 \otimes \mathrm{H}_{2} \mathrm{O}(741.15)$} & Chocolate brown & 63 & $58.30(58.26)$ & $4.30(4.22)$ & $15.00(15.11)$ & $7.30(7.54)$ \\
\hline 2 & $\mathrm{CoCl}_{2} \cdot 6 \mathrm{H}_{2} \mathrm{O}$ & {$\left[\mathrm{Co}(\mathrm{HL}) \mathrm{Cl}_{2}(791.37)\right.$} & Deep orange & 75 & $54.75(54.64)$ & $3.11(3.31)$ & $14.16(14.16)$ & $14.50(14.89$ \\
\hline 3 & $\mathrm{NiCl}_{2} \cdot 6 \mathrm{H}_{2} \mathrm{O}$ & {$\left[\mathrm{Ni}(\mathrm{HL})_{2}\right](661.31)$} & Lemon green & 48 & $65.89(65.40)$ & $4.00(3.96)$ & $16.81(16.95)$ & $8.70(8.88)$ \\
\hline 4 & $\mathrm{CuCl}_{2} \cdot 2 \mathrm{H}_{2} \mathrm{O}$ & {$\left[\mathrm{Cu}(\mathrm{L})\left(\mathrm{H}_{2} \mathrm{O}\right)\right](381.85)$} & Yellowish green & 80 & $56.74(56.61)$ & $3.50(369)$ & $14.60(14.67)$ & $16.55(16.64$ \\
\hline 5 & $\mathrm{VOSO}_{4} \cdot \mathrm{H}_{2} \mathrm{O}$ & {$\left[\mathrm{VO}\left(\mathrm{H}_{2} \mathrm{~L}\right)\left(\mathrm{SO}_{4}\right)\left(\mathrm{H}_{2} \mathrm{O}\right)\right](483.30)$} & Dark orange & 71 & $44.90(44.73)$ & $3.50(3.31)$ & $11.72(11.59)$ & - \\
\hline 6 & $\mathrm{PdCl}_{2}(1: 1)$ & {$\left[\mathrm{Pd}(\mathrm{L})\left(\mathrm{H}_{2} \mathrm{O}\right)\right](424.76)$} & Reddish brown & 82 & $50.70(50.90)$ & $3.15(3.30)$ & $13.20(13.19)$ & - \\
\hline 7 & $\mathrm{PdCl}_{2}(1: 2)$ & {$[\mathrm{Pd}(\mathrm{L})]_{2} \cdot \mathrm{EtOH}(859.6)$} & Coffee brown & 66 & $53.36(53.10)$ & $3.32(3.50)$ & $13.00(13.03)$ & - \\
\hline 8 & $\mathrm{PdCl}_{2}(2: 1)$ & {$\left[\mathrm{Pd}_{2}(\mathrm{HL}) \mathrm{Cl}_{3}(\mathrm{EtOH})\right](666.5)$} & Dark violet & 78 & $35.9(36.01)$ & $2.76(2.85)$ & $8.2(8.4)$ & - \\
\hline
\end{tabular}




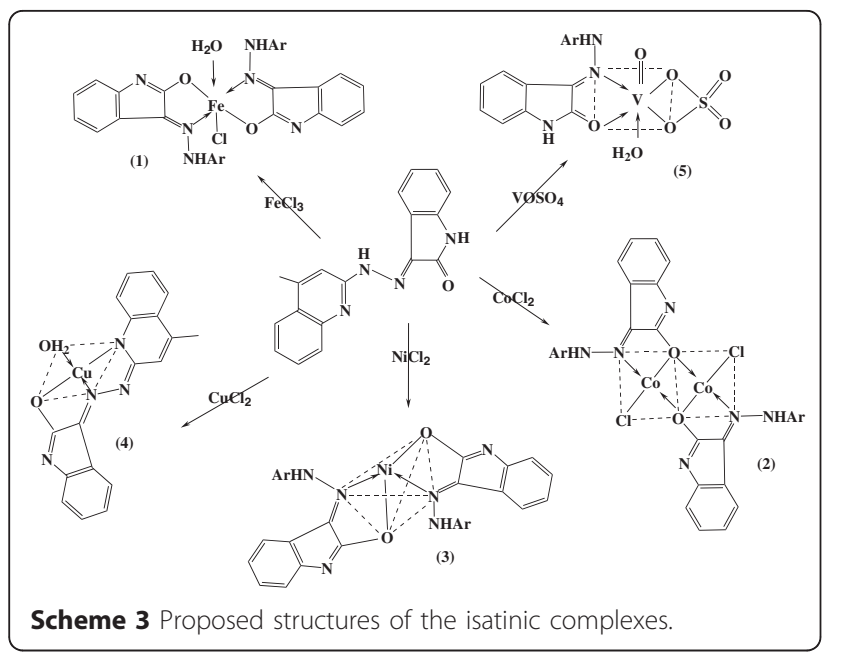

presence of one unpaired electron. In addition, the cobalt(II)-complex (2); $3 \mathrm{~d}^{7}$-system showed an effective magnetic moment of 1.46 B.M. confirming its square planar geometry which is related also to one unpaired electron. This value confirms its dimeric nature $\left(\mu_{\mathrm{eff}}<\right.$ 1.73 B.M.; spin only value in absence of a ligand field). In general, square planar complexes rather than tetrahedral complexes usually arise from strong field ligands, the stronger the ligand, the more favored is the trans isomer. On the other hand, the nickel(II)-complex (3); $3 d^{8}$ - system showed $\mu_{\text {eff }}$ value of 2.96 B.M. which is consistent with two unpaired electrons confirming its tetrahedral $\left(\mathrm{T}_{\mathrm{d}}\right)$ geometry (all square planar nickel(II)complexes are diamagnetic). Conversely, room temperature magnetic moment data (Table 3) showed the diamagnetism of the palladium(II)- complexes (6-8) in consistency with their square planar geometry; a general phenomenon for palladium(II)- complexes [14]. The ligands tending to give a strong field and to cause spin pairing give 4- or 5- rather than 6- coordinate complexes. The structure of the dimeric complex 7 has some interesting features; the $\mathrm{Pd}(\mathrm{II})$ - ions are at a center of a square plane of the chromophore $\mathrm{N}_{2} \mathrm{O}_{2}$. These

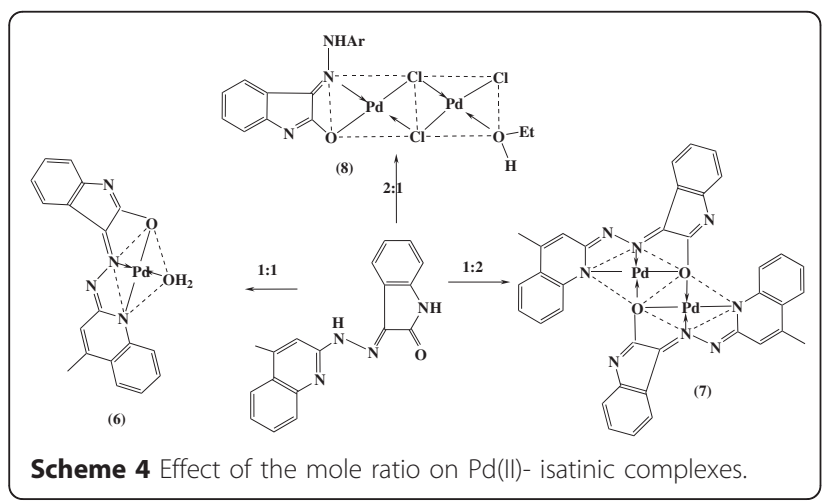

planes are stacked one above the other in the crystal, alternate molecules, being twisted through $90^{\circ}$, so the $\mathrm{Pd}(\mathrm{II})$ ions form chains with a Pd-Pd bond. Thus, the diamagnetic $\mathrm{Pd}(\mathrm{II})$ - complexes may be regarded as containing either square planar or tetragonally coordinated palladium with metal-metal bonding [19].

\section{Mass, ESR and electronic spectra}

The mass spectra of complexes 3; [Ni(HL) $\left.)_{2}\right],(661.31)$ and 6; $\left[\mathrm{Pd}(\mathrm{L})\left(\mathrm{H}_{2} \mathrm{O}\right)\right],(424.76)$ showed their molecular ion peaks at $m / z=660$ and 427 , respectively, confirming their suggested structures. On the other side, the electronic spectra of the complexes as DMF solutions are nearly similar in terms of the position, intensity and shape of the bands (Figure 3 and Table 3). They showed new intense broad bands in the range 504-518 nm confirming their charge transfer (CT) nature. Therefore, the color of all complexes is dominated by a CT transition which obscured the weak $d-d$ transitions occurring in the same region; a phenomenon encountered with isatinic complexes [20,21]. The X-band ESR spectrum of powdered sample of $\left[\mathrm{Cu}(\mathrm{L})\left(\mathrm{H}_{2} \mathrm{O}\right)\right](4)$ at room temperature exhibited one broad signal with $g=2.17$. The shape of the spectrum is consistent with the square-planar geometry around $\mathrm{Cu}(\mathrm{II})$ center in the complex [22]. Also, the X-band ESR spectrum of $\left[\mathrm{VO}\left(\mathrm{H}_{2} \mathrm{~L}\right)\left(\mathrm{SO}_{4}\right)\right.$ $\left.\left(\mathrm{H}_{2} \mathrm{O}\right)\right]$; 5 gave a broad homogeneous signal centered on $\mathrm{g}=2.12$ without resolved hyperfine structure; ${ }^{51} \mathrm{~V}(\mathrm{I}=$ $7 / 2, S=1 / 2$ ). The absence of vanadium's hyperfine coupling is common in the solid state and is attributed to the simultaneous flipping of neighboring electron spin or strong exchange interactions, which average out the interaction with the nuclei $[23,24]$. However the gvalues show positive deviation from the $\mathrm{g}=2.0023$ (the value of free electron), indicating a covalent character in the M-L bonding.

\section{Antimicrobial activity}

The antimicrobial activity of the ligand and its metal complexes were summarized in Table 4 and represented graphically in Figure 4. Inspection of the data revealed the following: a) The ligand lacks the antimicrobial activity. b) Also, complexes 1, 2 and 4 lack the antimicrobial activity towards Gram negative bacteria. c)

Table 3 Magnetic, conductivity and electronic spectral data of the isatinic complexes

\begin{tabular}{ccccccccc}
\hline Complex & $\mathbf{1}$ & $\mathbf{2}$ & $\mathbf{3}$ & $\mathbf{4}$ & $\mathbf{5}$ & $\mathbf{6}$ & $\mathbf{7}$ & $\mathbf{8}$ \\
\hline$\lambda(\mathrm{nm})$ & 490, & 490, & 490, & 491, & 491, & 504 & 508 & 490, \\
& 517 & 517 & 516 & 517 & 518 & & & 518 \\
$\mu_{\text {eff }}($ B.M. $)$ & 6.13 & 1.46 & 2.96 & 1.83 & 1.91 & \multicolumn{2}{c}{ Diamagnetic } \\
$(\Lambda)^{*}$ & 22 & 30 & 7 & 5 & 12 & 0.0 & 0.0 & 25 \\
\hline * Conductance $\left(\Omega^{-1} \mathrm{~cm}^{2} \mathrm{~mol}^{-1}\right)$ & & & & &
\end{tabular}



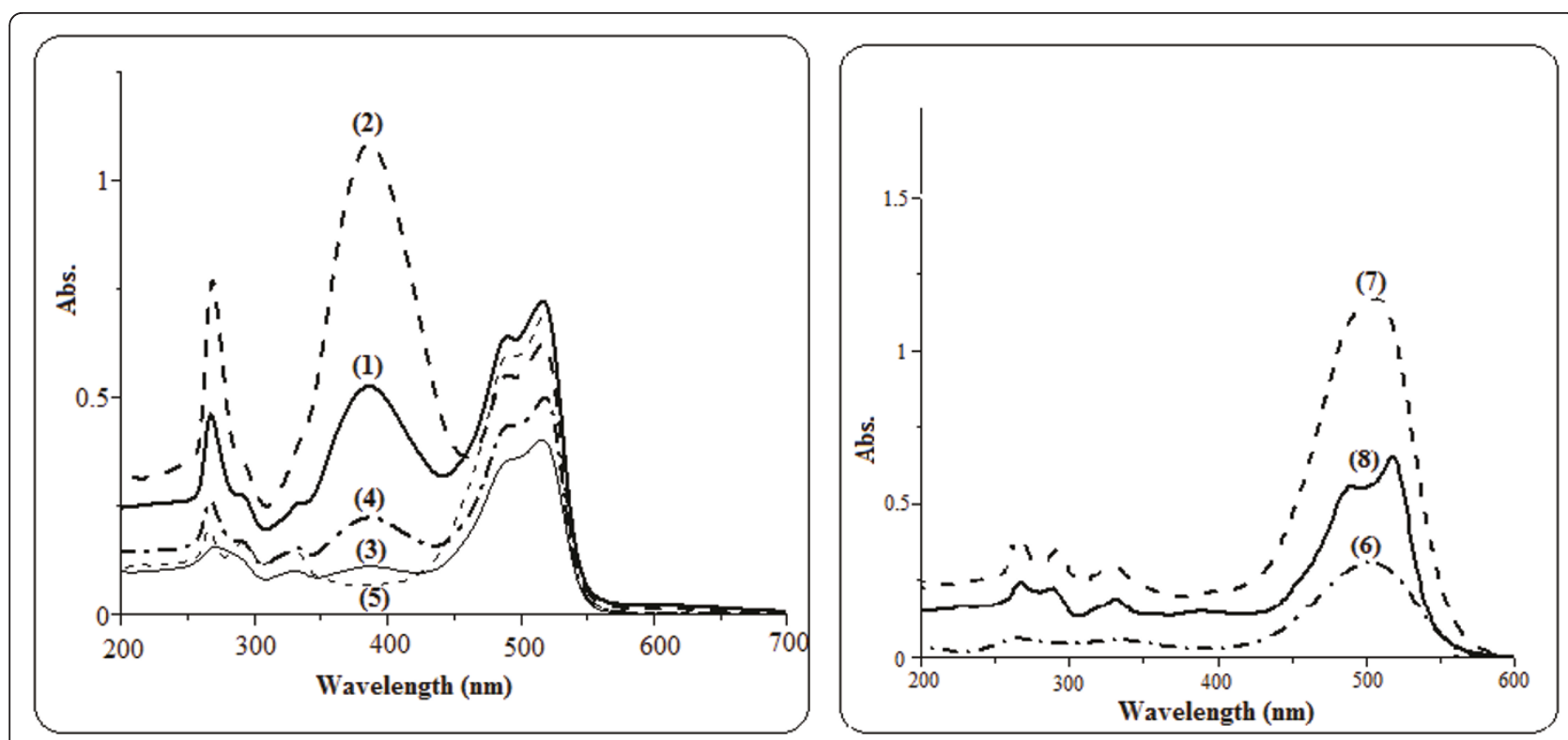

Figure 3 Electronic absorption spectra of the isatinic complexes in DMF.

Superiority of the binuclear $\mathrm{Pd}(\mathrm{II})$ - complex (8) against S. pyogenes bacteria $[25,26]$. d) The antimicrobial activity is highly influenced by the nature of the metal ion (Figure 4) and the order for Gram-positive bacteria (S. aureus) is as follows: Nickel(II) > Vanadyl(II) > Cobalt(II) > Copper(II) $\approx$ Palladium(II) $>>$ Iron(III). In this context, the activity of the isatinic complexes is related to the chelated indole ring [3]. The chelation increases the lipophilic character of the metal chelate and favors its permeation through the lipoid layer of the bacterial membranes $[27,28]$. e) Also, the degree of inhibition is influenced by the type of the coordinated anion as well as the concentration. f) Finally, all the investigated complexes exhibited low to moderate activities against the studied organisms relative to the standard

Table 4 Antimicrobial activity * of the $\mathrm{H}_{2} \mathrm{~L}$ and its complexes

\begin{tabular}{|c|c|c|c|c|c|c|c|c|}
\hline \multirow{4}{*}{ Complex } & \multicolumn{8}{|c|}{ Mean of zone diameter $(\mathrm{mm})$} \\
\hline & \multicolumn{4}{|c|}{ Gram - positive bacteria } & \multicolumn{4}{|c|}{ Gram - negative bacteria } \\
\hline & \multicolumn{2}{|c|}{ S. aureus } & \multicolumn{2}{|c|}{ S. pyogenes } & \multicolumn{2}{|c|}{ P. Phaseolicola } & \multicolumn{2}{|c|}{ P. fluorescens } \\
\hline & $\mathrm{a}$ & b & $a$ & b & $\mathrm{a}$ & $\mathbf{b}$ & $a$ & b \\
\hline $\mathrm{H}_{2} \mathrm{~L}$ & - & - & - & - & - & - & - & - \\
\hline 1 & 7 & - & 2 & - & - & - & - & - \\
\hline 2 & 16 & 6 & 3 & - & - & - & - & - \\
\hline 3 & 20 & 12 & 10 & 8 & 4 & - & 6 & - \\
\hline 4 & 14 & 6 & 6 & 2 & - & - & - & - \\
\hline 5 & 19 & 15 & 9 & 7 & 8 & 6 & 10 & 8 \\
\hline 8 & 13 & 10 & 17 & 12 & 10 & 9 & 12 & 9 \\
\hline Control \# & 42 & 28 & 38 & 30 & 36 & 25 & 38 & 30 \\
\hline
\end{tabular}

${ }^{*}$ The concentration is $2 \mathrm{mg} / \mathrm{mL}$ (a) and $1 \mathrm{mg} / \mathrm{mL}$ (b). reference (control). In conclusion, the isatinic complexes gave a fair inhibitor effect on growth of the microorganisms and were more potent as bacteriostatic agents.

\section{Experimental \\ Materials}

The chemicals used in this investigation were of the highest purity available (Merck, BDH, Aldrich and Fluka). They included copper(II), cobalt(II), nickel(II), palladium(II) and iron(III) chlorides, as well as vanadyl sulfate monohydrate. Also, they included aniline, ethyl acetoacetate, phosphorus oxychloride, hydrazine hydrate and isatin. Organic solvents were reagent grade chemicals and were used without further purification.

\section{Measurements}

Microanalyses were carried out on a Perkin- Elmer 2400 $\mathrm{CHN}$ elemental analyzer. Analyses of metal ions followed dissolution of the solid complex in hot concentrated nitric acid, $\mathrm{HNO}_{3}$, then diluting with doubly distilled water and filtration. The resultant solution was neutralized with ammonia and the metal ions were then titrated against EDTA. Electronic spectra were recorded on a Jasco V-550 UV/VIS spectrophotometer. IR spectra were recorded on a Bruker Vector 22 spectrometer using $\mathrm{KBr}$ pellets. ESR spectra were recorded on a Bruker Elexsys, E 500 operated at X-band frequency. Mass spectra were recorded either at $70 \mathrm{eV}$ on a gas chromatographic GCMSQP 1000-EX Shimadzu mass spectrometer or Direct Inlet unit (DI-50) of Shimadzu GC / MS - QP5050A. ${ }^{1} \mathrm{H}$ NMR spectra were recorded as $\mathrm{DMSO}-\mathrm{d}_{6}$ solutions on a Varian Mercury VX-300 NMR spectrometer using TMS as a reference. 


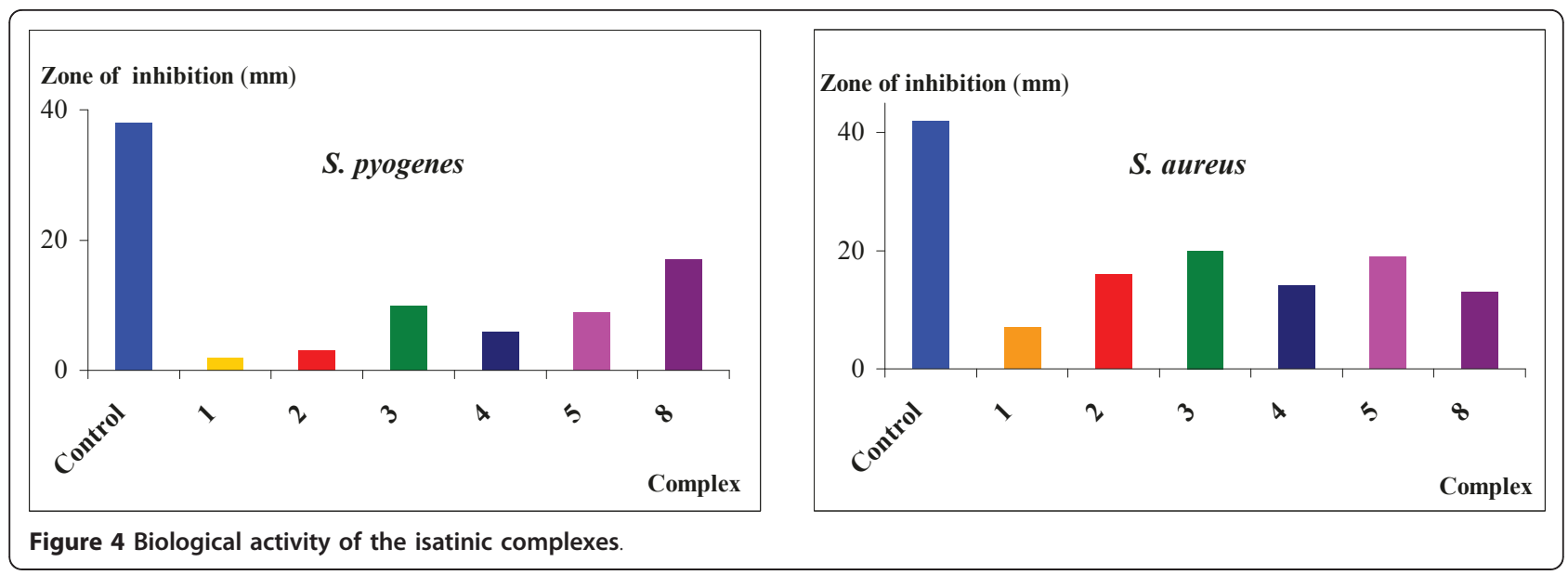

Molar conductivity was measured as DMF solutions on the Corning conductivity meter NY 14831 model 441. Magnetic susceptibility of the complexes was measured at room temperature using a Johnson Matthey, MKI magnetic susceptibility balance. Melting points were determined using a Stuart melting point apparatus.

\section{Preparation of the isatinic hydrazone [5-9]}

An ethanolic mixture of 2-hydrazinyl-4-methyl quinoline $(0.01 \mathrm{~mol})$ and isatin $(0.012 \mathrm{~mol})$ was refluxed for $15 \mathrm{~min}$. The formed scarlet red compound was filtered off, washed with ethanol and crystallized from DMF; Yield: $77 \%$ and m.p $302^{\circ} \mathrm{C}$.

\section{Preparation of the metal complexes}

Ethanolic solutions of the metal salt and the ligand were mixed in the mole ratio 1:1 (M:L) and refluxed for 2-4 hours depending on the nature of the isolated complexes (1-6). Also, the mole ratio 1:2 and 2:1 (M:L) was tried in case of $\mathrm{PdCl}_{2}$ (complexes 7 and 8). The resulting precipitates were filtered off, washed with ethanol then ether and finally air- dried. The results of elemental analysis and \% yield are shown in Table 2. All the isolated complexes are stable at room temperature, nonhygroscopic and insoluble in water and alcohols and soluble in DMSO and DMF. The melting points of the complexes were above $300^{\circ} \mathrm{C}$. The molar conductance of milli-molar DMF solutions indicates a non-electrolytic nature for all complexes (Table 3).

\section{Antimicrobial activity}

The standardized disc- agar diffusion method [29] was followed to determine the activity of the synthesized compounds against the sensitive organisms Staphylococcus aureus (ATCC 25923) and Streptococcus pyogenes (ATCC19615) as Gram- positive bacteria, Pseudomonas fluorescens (S 97) and Pseudomonas phaseolicola (GSPB 2828) as Gram- negative bacteria. The antibiotics chloramphencol and Cephalothin were used as standard reference in case of Gram- negative and Gram- positive bacteria, respectively. The tested compounds were dissolved in dimethyl formamide (DMF) which have no inhibition activity to get concentrations of $2 \mathrm{mg} / \mathrm{mL}$ and $1 \mathrm{mg} / \mathrm{mL}$. The test was performed on medium potato dextrose agar (PDA) which contain infusion of $200 \mathrm{~g}$ potatoes, $6 \mathrm{~g}$ dextrose and $15 \mathrm{~g}$ agar [29] Uniform size filter paper disks (3 disks per compound) were impregnated by equal volume $(10 \mu \mathrm{L})$ from the specific concentration of dissolved tested compounds and carefully placed on inoculated agar surface. After incubation for $36 \mathrm{~h}$ at $27^{\circ} \mathrm{C}$, inhibition of the organisms which evidenced by clear zone surround each disk was measured and used to calculate mean of inhibition zones.

\section{Conclusion and comments}

The effect of the type of the metal ion for the same anion $\left(\mathrm{Cl}^{-}\right)$is obvious from either the geometry of the isolated complexes $\left(\mathrm{O}_{h}, \mathrm{~T}_{\mathrm{d}}\right.$ and $\left.\mathrm{D}_{4 \mathrm{~h}}\right)$ or the various modes of bonding. The isatinic hydrazone uses its lactim form in all complexes $\left(\mathrm{Cl}^{-}\right)$except complex 5 with doubly charged $\mathrm{SO}_{4}{ }^{2-}$ anion in which it uses its lactam form. For the tetra-coordinated (tetrahedral or square planar) Co (II) and $\mathrm{Ni}$ (II)-complexes, their geometries are well defined by the magnetic measurements. Tetrahedral Co (II)- complexes have three unpaired electrons and square planar only one. Similarly, tetrahedral Ni(II)- complexes have two unpaired electrons and square planar are diamagnetic. Therefore, the obtained $\mu_{\text {eff }}$ values of 1.46 and 2.96 B.M. (Table 3) for $\mathrm{Co}(\mathrm{II})$ and $\mathrm{Ni}(\mathrm{II})$-complexes $(\mathbf{2 , 3})$ support the dimeric square planar of the former and a tetrahedral environment of the later. In case of Palladium (II)-complexes (6-8), the isatinic hydrazone produces ligand field strong enough to cause spin pairing. On the other hand, the antimicrobial activity is highly influenced by the nature of the metal ion and the order for $S$. aureus bacteria is as follows: Nickel(II) > Vanadyl(II) > Cobalt 
(II) $>$ Copper(II) $\approx$ Palladium(II) $>>$ Iron(III). Based on the above characterization, the proposed structures of the isatinic- complexes are shown in Schemes 3 and 4.

\section{Competing interests}

The author declares that they have no competing interests.

Received: 27 March 2011 Accepted: 27 June 2011

Published: 27 June 2011

\section{References}

1. Finar IL: Organic Chemistry. Hong Kong, The Continental Printing Co. Ltd. $61975,1$.

2. El-Behery $\mathrm{M}, \mathrm{El}$-Twigry $\mathrm{H}$ : Synthesis, magnetic, spectral, and antimicrobial studies of $\mathrm{Cu}(\mathrm{II}), \mathrm{Ni}(\mathrm{II}) \mathrm{Co}(\mathrm{II}), \mathrm{Fe}(\mathrm{III})$, and $\mathrm{UO}_{2}(\mathrm{II})$ complexes of a new Schiff base hydrazone derived from 7-chloro-4-hydrazinoquinoline. Spectrochimica Acta (A) 2007, 66:28-36.

3. Akbar Ali M, Mirza AH, Hjh Junaidah Hj, Bakar Abu, Bernhardt Paul V: Preparation and structural characterization of nickel(II), cobalt(II), zinc(II) and tin(IV) complexes of the isatin Schiff bases of S-methyl and Sbenzyldithiocarbazates. Polyhedron 2011, 30:556-564.

4. Singh DP, Malik V, Kumar K, Sharma C, Aneja KR: Macrocyclic metal complexes derived from 2,6-diaminopyridine and isatin with their antibacterial and spectroscopic studies. Spectrochimica Acta (A) 2010, 76:45-49.

5. Seleem HS, El-Inany GA, El-Shetary BA, Mousa M: The ligational behavior of a phenolic quinolyl hydrazone towards copper(II)- ions. Chemistry Central Journal 2011, 5:2.

6. Seleem HS, Mostafa M, Hanafy FI: Stability of transition metal complexes involving three isomeric quinolyl hydrazones. Spectrochim Acta (A) 2011, 78:1560-1566

7. Seleem HS, El-Inany GA, Eid MF, Mousa M, Hanafy Fl: Complexation of some hydrazones bearing the quinoline ring. Potentiometric studies. J Barz Chem Soc 2006, 17:723-729.

8. Seleem HS, El-Inany GA, Mousa M, Hanafy FI: Spectroscopic studies on 2[2-(4- methylquinolin-2-yl)hydrazono]-1,2-diphenylethanone molecule and its metal complexes. Spectrochim Acta (A) 2009, 74:869-874.

9. Seleem HS, El-Inany GA, Mousa M, Hanafy FI: Spectroscopic and pH-metric studies of the complexation of 3-[2-(4-methylquinolin-2-yl)hydrazono] butan-2-one oxime compound. Spectrochim Acta (A) 2010, 75:1446-1451.

10. Seleem HS, El-Inany GA, El-Shetary BA, Mousa M, Hanafy FI: The ligational behavior of an isatinic quinolyl hydrazone towards copper(II)- ions. Chemistry Central Journal 2011, 5:20.

11. Burgess J: Metal lons in Solution. Great Britain, Wiley; 1981

12. Gutmann V: The Donor-Acceptor Approach to Molecular Interactions. Plenum Press, New York, London; 1978.

13. Taha A, Mageed Kiwan A: Preferential solvation and molecular orbital calculation studies of solvatochromic mesoionic 2,3-diaryl-2Htetrazolium-5-thiolate. New J Chem 2001, 25:502-508.

14. Jain VK, Jain L: The chemistry of binuclear palladium(II) and platinum(II) complexes. Coordination Chemistry Reviews 2005, 249:3075-3197.

15. Efthymiou CG, Kitos AA, Raptopoulou CP, Perlepes SP, Escuer A, Papatriantafyllopoulou C: Employment of the sulfate ligand in 3d-metal cluster chemistry: A novel hexanuclear nickel(II) complex with a chair metal topology. Polyhedron 2009, 28:3177-3184.

16. Nakamoto K: Infrared and Raman Spectra of Inorganic and Coordination Compounds. Wiley, New York; 51997.

17. Bozkurt E, Doner A, Ucar I, Karabulut B: Synthesis, crystal structure, EPR spectra of $\mathrm{Cu}^{2+}$ doped catena- poly [[diaquabis(methylisonicotinate- $\mathrm{N}$ ) cadmium(II)]-I-(sulfato-O:O)] single crystal. Chemical Physics Letters 2011, 502:163-168.

18. Ismail TMA: Synthesis, characterization and biological activities of mononuclear and binuclear Fe(III) complexes with some symmetric and unsymmetric Schiff-Base ligands. J Coord Chem 2006, 59:255-270.

19. Nicholls D: Complexes and First-Row Transition Elements. Macmillan Press Ltd, London; 1981

20. Gupta LK, Bansal U, Chandra S: Spectroscopic and physicochemical studies on copper(II) complexes of isatin-3,2'-quinolyl-hydrazones and their adducts. Spectrochim Acta (A) 2006, 65:463-466.
21. Gupta LK, Bansal U, Chandra S: Spectroscopic and physicochemical studies on nickel(II) complexes of isatin-3,2'-quinolyl-hydrazones and their adducts. Spectrochim Acta (A) 2007, 66:972-975.

22. Emara AAA, El-Sayed BA, Ahmed AE: Syntheses, spectroscopic characterization and thermal behavior on novel binuclear transition metal complexes of hydrazones derived from 4,6-diacetylresorcinol and oxalyldihydrazine. Spectrochim Acta (A) 2008, 69:757-769.

23. Bencini A, Gattechi D: EPR of Exchange Coupled Systems. SpringerVerlach, Berlin; 1990

24. Abou-Hussen AA, El-Metwally NM, Saad EM, El-Asmy AA: Spectral, magnetic, thermal and electrochemical studies on phthaloyl bis (thiosemicarbazide) complexes. J Coord Chem 2005, 58:1735-1749.

25. Tusek-Bozic L, Juribasic M, Traldi P, Scarcia V, Furlani A: Synthesis, characterization and antitumor activity of palladium(II) complexes of monoethyl 8- quinolyl methylphosphonate. Polyhedron 2008, 27:1317-1328.

26. Zhang J, Li L, Wang L, Zhang F, Li X: Synthesis, characterization and cytotoxicity of mixed-ligand complexes of palladium(II) with aromatic diimine and 4-toluenesulfonyl-L-amino acid dianion. European Journal of Medicinal Chemistry 2010, 45:5337-5344.

27. Imran M, lqbal J, lqbal S, ljaz N: In Vitro Antibacterial Studies of Ciprofloxacin-imines and Their Complexes with $\mathrm{Cu}(\mathrm{II}), \mathrm{Ni}(\mathrm{II}), \mathrm{Co}(\mathrm{II})$, and $\mathrm{Zn}$ (II). Turk J Biol 2007, 31:67-72.

28. Raman N, Johnson S, Sakthivel A: Transition metal complexes with Schiffbase ligands: 4-aminoantipyrine based derivatives-a review. Journal of Coordination Chemistry 2009, 62:691-709.

29. Rahman AU, Choudhary MI, Thomsen WJ: Bioassay Techniques for drug development. The Netherlands, Harwood Academic Publishers; 2001.

doi:10.1186/1752-153X-5-35

Cite this article as: Seleem: Transition metal complexes of an isatinic quinolyl hydrazone. Chemistry Central Journal 2011 5:35.

\section{Publish with ChemistryCentral and every scientist can read your work free of charge \\ "Open access provides opportunities to our colleagues in other parts of the globe, by allowing anyone to view the content free of charge." W. Jeffery Hurst, The Hershey Company.}

- available free of charge to the entire scientific community

- peer reviewed and published immediately upon acceptance

- cited in PubMed and archived on PubMed Central

- yours - you keep the copyright

Submit your manuscript here:

http://www.chemistrycentral.com/manuscript/<smiles>c1ccccc1</smiles>

ChemistryCentral 